\title{
- Common Symptoms Experienced by Cancer Patients Undergoing Chemotherapy
}

\section{IICRR}

Section: Healthcare

ISI Impact Factor

(2019-20): 1.628

IC Value (2019): 90.81

$\operatorname{SJIF}(2020)=7.893$

(c) (i) (3)

Copyright@IJCRR

\section{Uppu Praveen ${ }^{1}$, Meenakshisundaram Manickavasagam², Sirala Jagadeesh Nalini ${ }^{3}$}

'Research Scholar (Nursing), Sri Ramachandra Institute of Higher Education \& Research, Chennai-6oo 116, India; 2 Professor \& Head, Department of Medical Oncology, Sri Ramachandra Institute of Higher Education and Research (DU), Porur, Chennai - 6oo 116, India; 3Professor \& Principal, Faculty of Nursing, Sri Ramachandra Institute of Higher Education and Research (DU), Porur, Chennai - 60o 116, India.

\section{ABSTRACT}

Introduction: Chemotherapy is one of the most commonly used treatments of choice for cancer and it leads to certain side effects. The oncology care team needs to identify the symptoms experienced by cancer patients who are under chemotherapy to resolve these side effects.

Objective: To identify the most common side effects experienced by cancer patients undergoing chemotherapy.

Methods: A cross-sectional survey is carried out in the Medical Oncology Outpatient department and Chemotherapy Units of Sri Ramachandra Hospital, Sri Ramachandra Institute of Higher Education, and Research (DU), Chennai, India, from February to March 2020. A convenient sampling technique was used to recruit a total of 150 cancer patients. Data collection was done through personal interviews and a review of their medical records. Approximately 15-20 minutes was required to obtain data from each participant.

Results: Most (31\%) of them had breast cancer, $21 \%$ of them had gynaecological tract cancer, around $20 \%$ of them had digestive tract cancer. Fatigue was the most (48\%) commonly reported symptom, followed by vomiting (36\%) and pain (29.3\%). Other symptoms like itching, oral mucositis, urinary problems, dyspnoea were experienced by the cancer patients under chemotherapy.

Conclusion: This study will help the oncology care team to understand the most common symptoms experienced by cancer patients who underwent chemotherapy. Identification and management of these symptoms will help the cancer patients to have adherence to the treatment.

Key Words: Common symptoms, Side effects, Chemotherapy, Quality of life, Cancer patients

\section{INTRODUCTION}

Every year more than 12 million new cancer cases are diagnosed across the globe. Different treatment modalities were also introduced and improved along with the increase in the prevalence of cancer. Chemotherapy is one of the most commonly used treatments of choice for cancer. ${ }^{1}$ The nature of Chemotherapy is to damage the cancer cells along with healthy cells which result in the development of certain side effects. ${ }^{2}$ The side effects of chemotherapy can be common among cancer patients and may result in life-threatening. Even cancer patients may experience these side effects when they are at home. ${ }^{3}$

The side effects result in certain manifestations like fatigue, loss of appetite nausea $\&$ vomiting, diarrhoea, constipation, insomnia, etc., which has an impact on cancer patients' quality of life and may disturb the continuity of the treatment. ${ }^{4}$

The oncology care team needs to identify the symptoms experienced by the cancer patients who are under chemotherapy to resolve these side effects so that it can help cancer patients and the oncology care team to render continuity in treatment. ${ }^{5}$

Purpose/objective: To identify the most common side effects experienced by cancer patients undergoing chemotherapy.

\section{METHODS}

\section{Study design and Setting}

A cross-sectional survey is carried out in the Medical Oncology Outpatient department and Chemotherapy Units of Sri

\section{Corresponding Author:}

Mr. Uppu Praveen, Ph.D. Scholar, C/o Faculty of Nursing, Sri Ramachandra Institute of Higher Education \& Research, No.1 Ramachandra Nagar, Porur, Chennai-600 116, India; Cell: 7204286978, 9441841884; Email: uppupraveen@yahoo.com

ISSN: 2231-2196 (Print)

Received: 05.03 .2021
ISSN: 0975-5241 (Online)

Revised: 23.04 .2021
Accepted: 17.05 .2021
Published: 24.10 .2021 
Ramachandra Hospital, Sri Ramachandra Institute of Higher Education and Research (DU), Chennai, India, from February to March 2020.

\section{Sample}

A convenient sampling technique was used to recruit a total of 150 cancer patients. The following criteria were used to include the participants in this study

a) Cancer patients who are receiving Chemotherapy at any stage and any cycle.

b) Who is willing to participate in study

c) Both genders of 18 years of age or older than 18 years.

d) Who can speak and understand English and /or Tamil.

\section{Data Collection Tool}

It consists of 8 items related to the cancer patient's personal and clinical information i.e. Age in years, gender, type of cancer, duration of treatment, stage of cancer, cycles of Chemotherapy completed, type of Chemotherapy, side effects/symptoms experienced.

\section{Data collection procedure}

The participants who met the eligibility criteria were invited to participate in the study. Informed consent was obtained from the participants. The participant's personal and clinical information was obtained by the researcher through personal interviews and a review of their medical records. Approximately 15-20 minutes was required to obtain data from each participant.

\section{Ethical considerations}

Ethical approval was obtained from the Institutional Ethics Committee of Sri Ramachandra Institute of Higher Education Research (DU). Informed consent was obtained from the participants. The anonymity of the participants was maintained. (IEC-NI/19/JUL/70/45)

\section{Statistical analysis}

Data analysis was performed by using R-Studio Version 3.6.2. Descriptive statistics like frequency and percentages were used to represent the participant's characteristics, clinical information, and common symptoms experienced by them.

\section{RESULTS}

Out of 150 participants, the majority (53.5\%) were $\leq 55$ years of age, most $(66 \%)$ of them were females, around $60.7 \%$ of them have $\leq 4$ months duration of treatment, the majority $(59.3 \%)$ of them completed $\leq 5$ cycles of chemotherapy, around $58 \%$ of them on curative chemotherapy, about $42.7 \%$ of them on IV stage of cancer, $21.3 \%$ of them on III stages of cancer (Table 1).
Regarding types of cancer, the majority $(31.3 \%)$ of them were diagnosed with Breast cancer, around $14 \%$ of them had Ovarian cancer, $8.6 \%$ of them had rectal cancer, about $6.7 \%$ of them had Lung cancer and stomach cancer respectively, $4 \%$ of them had Cervical cancer and Multiple Myeloma respectively, $3.3 \%$ of them had Oesophageal cancer and endometrial cancer respectively, $2.7 \%$ of them had colon cancer, $2 \%$ of them had Prostate cancer (Table 2 ).

The majority (48\%) of them experiencing fatigue as a common symptom, $36 \%$ of them experiencing vomiting, around $29 \%$ of them experiencing pain, about $26.7 \%$ of them experiencing loss of appetite, $23.3 \%$ of them experiencing nausea, $12.7 \%$ of them complains of disturbed sleep, $9.3 \%$ of them experiencing constipation, around $7.3 \%$ of them complaining diarrhoea, about $5.3 \%$ of them complained itching, $4.7 \%$ of them experienced fever, $4 \%$ of complained oral mucositis, only $3.3 \%$ of them experienced urinary problems and $1.3 \%$ of them complained about dyspnoea and stomach fullness. (Table 3).

\section{DISCUSSION}

This study shows that $53.5 \%$ of them were in the age group of $\leq 55$ years, $66 \%$ of them were females and $59.3 \%$ of them completed more than 5 cycles of chemotherapy and $42.7 \%$ of them were in the IV stage of cancer which was similar to those reported in other studies performed by Pearce and Wochen. ${ }^{2,3}$

Most (31\%) of them had breast cancer, $21 \%$ of them had gynaecological tract cancer, around $20 \%$ of them had digestive tract cancer and $6.7 \%$ of them had lung cancer which was similar to those reported by Wochna and Nayak. ${ }^{3,5}$

Fatigue was the most (48\%) commonly reported symptom, followed by vomiting (36\%) and pain $(29.3 \%)$. Which was similar to those reported in other studies ${ }^{1,2,5}$. Loss of appetite (26.7\%), nausea (23.3\%) and disturbed sleep (12.7\%) constipation $(9.3 \%)$, and diarrhoea $(7.3 \%)$ were frequent symptoms experienced by the cancer patients under chemotherapy. ${ }^{6,7,8}$

Other symptoms like itching, fever, oral mucositis, skin/nail discolouration, numbness, urinary problems, dyspnoea, and stomach fullness were reported by the chemotherapy cancer patients. ${ }^{9,10}$

\section{CONCLUSION}

Chemotherapy is one of the most widely used treatment modalities for cancer and it leads to certain side effects. This study will help the oncology care team to understand the most common symptoms experienced by cancer patients who underwent chemotherapy. The symptoms like fatigue, 
vomiting, pain, loss of appetite, nausea and disturbed sleep, etc. Identification and management of these symptoms will help the cancer patients to have adherence to the treatment and leads to improvement in the quality of life.

\section{ACKNOWLEDGEMENT}

I would like to acknowledge Dr. P. Jovita M. Martin, Associate Consultant, Dr. A Ravichandran, Assistant Physician, Dr. Hannesha P, Senior Resident, Dr. Kumanan J, Senior Resident, Department of Medical Oncology, Sri Ramachandra Institute of Higher Education \& Research (DU) for their immense support. The authors are also grateful to authors/editors/publishers of all those articles, journals from where the literature for this article has been reviewed and discussed.

\section{Financial support: Nil}

\section{Conflict of interest: Nil}

\section{Author's Contribution:}

Mr. Uppu Praveen: Conception and design of the study, acquisition of the data, analysis and interpretation of the data, drafting of the manuscript, approval of the version of the manuscript to be published.

Dr. Meenakshisundaram Manickavasagam: Conception and design of the study, acquisition of the data, drafting of the manuscript, revising the manuscript critically for important intellectual content, approval of the version of the manuscript to be published.

Dr. Sirala Jagadeesh Nalini: Conception and design of the study, revising the manuscript critically for important intellectual content, approval of the version of the manuscript to be published.

\section{REFERENCES}

1. Chan HK, Ismail S. Side Effects of Chemotherapy among Cancer Patients in a Malaysian General Hospital: Experiences, Perceptions and Informational Needs from Clinical Pharmacists. Asian Pac J Cancer Prev. 2014 Jul 15;15(13):5305-9.

2. Pearce A, Haas M, Viney R, Pearson SA, Haywood P, Brown C. Incidence and severity of self-reported chemotherapy side effects in routine care: A prospective cohort study. Ganti AK, editor. PLOS ONE. 2017 Oct ;12(10):e01843-60.

3. Wochna LV. Symptom Experience in Older Adults Undergoing Treatment for Cancer. Oncology Nursing Forum. 2015 May 1;42(3): E269-78.

4. Weaver A, Young AM, Rowntree J, Townsend N, Pearson S, Smith J. Application of mobile phone technology for managing chemotherapy-associated side-effects. Annals of Oncology. 2007 Nov;18(11):1887-92.

5. Nayak MG, George A, Vidyasagar MS, Mathew S, Nayak S, Nayak BS. Quality of Life among Cancer Patients. Indian J Palliat. Care 2017 Dec;23(4):445-50.

6. Moradian S, Howell D. Prevention and management of chemotherapy-induced nausea and vomiting. Int J Palliat Nurs. 2015 May 2; 21(5):216-24.

7. Yao Y, Ji C, He Y, Pan Y. Relationship between Helicobacter pylori infection and vomiting induced by gastrointestinal cancer chemotherapy: Helicobacter pylori infection and CINV. Intern Med. J.2017 Jul;47(7):792-7.

8. Di R, Li G. Use of a smartphone medical app improves complications and quality of life in patients with nasopharyngeal carcinoma who underwent radiotherapy and chemotherapy. Medical science monitor: Med Sci Mon Int Med J Exp Clin Res. 2018;(24):6151-56.

9. Kearney N, McCann L, Norrie J, Taylor L, Gray P, McGeeLennon M, et al. Evaluation of a mobile phone-based, advanced symptom management system (ASyMSC) in the management of chemotherapy-related toxicity. Supp Care Canc. 2009;17(4):437-44.

10. Carelle N, Piotto E, Bellanger GJ, Thuillier A, Khayat D. Changing patient perceptions of the side effects of cancer chemotherapy. Cancer. 2002;95:(1)155-163.

Table 1: Personal characteristics and clinical information $(\mathrm{N}=\mathbf{1 5 0})$.

$\begin{array}{lcc}\text { Variable } & \text { n } & \% \\ \text { Age in years } & & 55 \cdot 3 \\ \leq 55 & 83 & 44 \cdot 7 \\ >55 & 67 & 34.0 \\ \text { Gender } & & 66.0 \\ \text { Male } & 51 & \\ \text { Female } & 99 & 60.7 \\ \text { Duration of Treatment in months } & & 39 \cdot 3 \\ \leq 4 & 91 & \\ >4 & 59 & 59 \cdot 3 \\ \text { No. of chemotherapy cycles completed } & & 40.7 \\ \leq 5 & 89 & 61\end{array}$


Table 1: (Continued)

Variable

$\mathbf{n}$

Type of Chemotherapy

Curative

$87 \quad 58.0$

Palliative

Stage of cancer

Stage 1

$14 \quad 9.3$

Stage 2

29

$19 \cdot 3$

Stage 3

32

21.3

Stage 4

Lipid Stage

4

Not applicable

7

Table 2: Distribution of sample based on Types of cancer. $(\mathrm{N}=150)$

\begin{tabular}{|c|c|c|}
\hline Type of cancer & $\mathbf{n}$ & $\%$ \\
\hline Breast cancer & 47 & 31.3 \\
\hline Ovarian cancer & 21 & 14.0 \\
\hline Cervical cancer & 6 & 4.0 \\
\hline Endometrial cancer & 5 & $3 \cdot 3$ \\
\hline Lung cancer & 10 & 6.7 \\
\hline Stomach cancer & 10 & 6.7 \\
\hline Colon cancer & 4 & 2.7 \\
\hline Rectal cancer & 13 & 8.6 \\
\hline Gastro-Intestinal stomal tumor & 1 & 0.7 \\
\hline Cecum cancer & 2 & 1.3 \\
\hline Esophageal cancer & 5 & $3 \cdot 3$ \\
\hline Hepatocellular Carcinoma & 2 & 1.3 \\
\hline Pancreatic cancer & 2 & 1.3 \\
\hline Prostate cancer & 3 & 2.0 \\
\hline Buccal Mucosa cancer & 2 & 1.3 \\
\hline Tongue cancer & 1 & 0.7 \\
\hline Laryngeal cancer & 1 & 0.7 \\
\hline Multiple Myeloma & 6 & 4.0 \\
\hline Hodgkin Lymphoma & 1 & 0.7 \\
\hline Non- Hodgkin Lymphoma & 1 & 0.7 \\
\hline Pre-ampullary Carcinoma & 2 & 1.3 \\
\hline Germ cell tumor & 1 & 0.7 \\
\hline Synovial sarcoma & 2 & 1.3 \\
\hline Anaplastic large cell lymphoma & 1 & 0.7 \\
\hline Ewing's sarcoma & 1 & 0.7 \\
\hline
\end{tabular}


Table 3: Common symptoms experiencing by cancer patients

\begin{tabular}{lll} 
Symptoms experiencing & n & \% \\
Fatigue & 72 & 48.0 \\
Vomiting & 54 & 36.0 \\
Pain & 44 & 29.3 \\
Loss of appetite & 40 & 26.7 \\
Nausea & 25 & 23.3 \\
Disturbed sleep & 19 & 12.7 \\
Constipation & 14 & $9 \cdot 3$ \\
Diarrhea & 11 & $7 \cdot 3$ \\
Itching & 8 & $5 \cdot 3$ \\
Fever & 7 & 4.7 \\
Oral Mucosities & 6 & 4.0 \\
Skin/nail discoloration & 6 & 4.0 \\
Numbness & 5 & 3.3 \\
Urinary problems & 5 & 3.3 \\
Dyspnea & 5 & 1.3 \\
Stomach fullness & 2 & 1.3 \\
\hline
\end{tabular}

